\title{
ТРАНСФОРМАЦИЯ ОРГАНИЗАЦИИ ТРУДА И СОЦИАЛЬНО-ТРУДОВОГО МОНИТОРИНГА В УСЛОВИЯХ ПЕРЕХОДА НА УДАЛЕННУЮ РАБОТУ 1
}

\section{TRANSFORMATION OF THE LABOUR ORGANIZATION AND SOCIAL AND LABOR MONITORING IN THE CONDITIONS OF THE TRANSITION TO REMOTE WORK}

Yu. Shulgina

Yu. Vertakova

I. Maltseva

V. Plotnikov

Summary: The development of information and communication technologies and the transformation of the sectoral structure of employment have made employment in a remote format possible for a wide range of professions. In 2020, against the backdrop of the COVID-19 pandemic, many organizations are faced with the need to transfer many office workers to teleworking mode. For organizations that were already working with high virtualization, the activities remained almost unchanged, while others faced serious difficulties, both technical and organizational. Employees had to rethink the principles of interaction with the organization, and managers had to master the management of remote workers. In such conditions, the issues of transformation of the system of labor organization and social and labor monitoring during the transition to remote work acquired importance.

The purpose of this article is to analyze the practice of organizing work and social and labor monitoring accumulated during the pandemic during the transition to remote work. The paper highlights the main differences between remote and remote work, analyzes the advantages and disadvantages of remote employment, systematizes tools to improve the efficiency of organizing work processes in a remote format.

Keywords: remote work, social and labor monitoring, transformations in the labor market, labor organization.
Шульгина Юлия Валерьевна

аспирант, ФГБОУ ВО «Юго-Западный государственный университет» (2. Курск)

jvl@inbox.ru

Вертакова Юлия Владимировна

Д.э.н., профессор, Курский филиал ФГОБУ ВО «Финансовый университет при Правительстве РФ»; ФГБОУВО «Юго-Западный государственный университет» (г. Курск) vertakova7@yandex.ru

Мальчева Ирина Федоровна К.э.н., дочент, ФГБОУ ВО

«Юго-Западный государственный университет» (2. Курск) irina-fedorovna@inbox.ru

Плотников Владимир Александрович Д.э.н., професссор, ФГБОУВО «Юго-Западный государственный университет» (г. Курск); ФГБОУ ВО «Санкт-Петербургский государственный экономический

университет»

Plotnikov_2000@mail.ru

Аннотация: Развитие информационно-коммуникационных технологий и трансформация отраслевой структуры занятости сделали возможной занятость в удаленном формате для достаточно широкого спектра профессий и видов экономической деятельности. В 2020 году на фоне пандемии COVID-19 многие организации столкнулись с необходимостью перевода в дистанционный режим работы большого количества офисных сотрудников. Для организаций, уже работавших с высокой степенью виртуализации менеджмент-процессов, деятельность почти не претерпела изменений, другие же столкнулись с серьезными трудностями как технического, так и организационного плана. Сотрудникам пришлось пересмотреть принципы взаимодействия с организацией, а менеджерам освоить управление удаленными работниками. В таких условиях особую значимость приобрели вопросы трансформации подходов к организации труда и социально-трудового мониторинга при переходе на удаленную работу.

Цель настоящей статьи - проанализировать накопленную за период пандемии практику организации труда и социально-трудового мониторинга в условиях перехода на удаленную работу. В работе выделены основные различия между дистанционной и удаленной работой, проанализированы преимущества и недостатки удаленной занятости, систематизированы инструменты, позволяющие повысить эффективность организации рабочих процессов в дистанционном формате.

Ключевые слова: удаленная работа, социально-трудовой мониторинг, трансформации на рынке труда, организация труда.

Исследование выполнено при поддержке гранта Президента РФ по государственной поддержке ведущих научных школ РФ № НШ-2702.2020.6 «Концептуальные основы новой парадигмы экономического развития в эпоху технологической и социальной трансформации». 


\section{Введение}

$\mathrm{B}$ 2020 году российская экономика столкнулась с новым вызовом - пандемией COVID-19, которая кардинально изменила процессы нормальной деятельности во многих отраслях [1]. Эти процессы структурных трансформаций еще далеки от завершения [2, 3 и др.], что определяется как наступившей «второй волной» инфекционного заболевания и связанными с ней социальными и экономическими ограничениями, так и пролонгированным эффектом влияния «первой волны».

Естественно, что пандемия большинством авторов рассматривается как негативный фактор, деструктивно повлиявший на уровень социально-экономического развития и темпы экономического роста. Пандемия послужила триггером для запуска глобального экономического кризиса [4]. С другой стороны, она инициировала и положительные изменения во многих областях. Некоторые же из изменений, в силу «аберрации близости» (термин профессора Л.Н. Гумилева), пока что трудно оценить, т.к. они носят противоречивый характер.

В частности, это касается вопроса достаточно массового перевода сотрудников российских организаций на удаленный режим работы. В этой связи, цель настоящей статьи - проанализировать накопленную за период пандемии практику организации труда и социально-трудового мониторинга в условиях перехода на удаленную работу.

\section{Нормативно-правовые предпосылки уАаленной работы}

Трудовой кодекс Российской Федерации - ключевой нормативно-правовой акт, регламентирующий трудовые отношения в России. Казалось бы, длительный период применения его положений, высокая степень отработанности соответствующих процедур не оставляют возможностей для каких-либо пробелов в регулировании. Однако макроэкономический шок, вызванный пандемией COVID-19, показал, что это не совсем так.

Массовый и одномоментный переход на дистанционную работу в Российской Федерации выявил ряд проблем, которые должны решаться на уровне государства, а не отдельных организаций. В этой связи было выпущено письмо Министерства труда и социальной защиты Российской Федерации от 23 апреля 2020 г. № 14-2/10/ П-3710 «О направлении рекомендаций по применению гибких форм занятости в условиях предупреждения распространения новой коронавирусной инфекции на территории РФ», которое содержит следующие рекомендации [5]:

1. осуществить переход на удаленную работу всех работников, для которых существуют такие техни- ческие возможности;

2. заключить трудовой договор о дистанционной работе с работниками, которые используют для выполнения своей трудовой функции и для осуществления взаимодействия между работодателем и работником по вопросам, связанным с ее выполнением, информационно-телекоммуникационные сети общего пользования;

3. организовать надомную работу.

Таким образом, можно сделать вывод, что Министерство труда и социальной защиты РФ разграничивает понятия «дистанционной», «удаленной» и «надомной» работы. Мало того, следует специально подчеркнуть, что Трудовой кодекс регламентирует работу надомников (глава 49) и дистанционных работников (глава 49.1). Понятие «удаленной работы» в российском законодательстве не раскрыто, что порождает неоднозначность его толкования на практике и правовую неопределенность.

Отметим, что ст. 312.1 ТК РФ содержит следующее определение: «Дистанционной работой является выполнение определенной трудовым договором трудовой функции вне места нахождения работодателя, его филиала, представительства, иного обособленного структурного подразделения (включая расположенные в другой местности), вне стационарного рабочего места, территории или объекта, прямо или косвенно находящихся под контролем работодателя, при условии использования для выполнения данной трудовой функции и для осуществления взаимодействия между работодателем и работником по вопросам, связанным с ее выполнением, информационно-телекоммуникационных сетей общего пользования, в том числе сети Интернет» [6].

Сложившаяся практика понимания удаленной работы, как одной из форм нестандартной занятости [7], несколько шире. Она допускает смешанный режим трудовой деятельности, когда часть времени работник проводит на территории работодателя (в офисе), а часть - за ее пределами. Н.Л. Лютов ссылается на практику Европейского Союза, где разграничивают «телеработу» (дистанционную работу) и «мобильную работу» (удаленную работу). Если в первом случае рабочее место не принадлежит работодателю, но фиксировано (например, это может быть место проживания работника), то во втором никакой конкретизации, где работник будет выполнять свои обязанности, не предусмотрено [8].

Таким образом, мы предлагаем понимать удаленную работу более широко, в сравнении с дистанционной работой, при этом, принимая во внимание тот факт, что в условиях самоизоляции и иных социальных ограничений, объявленных во многих регионах РФ в 2020 году в связи с пандемией COVID-19, в большинстве случаев удаленная работа подразумевала нахождение работни- 
ка именно по месту проживания.

\section{Оченка распространенности удаленной работы, ее недостатков и преимушеств}

Отметим, что число вакансий, предполагающих удаленную занятость, в общем объеме вакансий на российском рынке труда увеличилось за последний год существенно: с 2\% в сентябре 2019 года до 3,5\% в сентябре 2020 года. При этом, согласно данным исследования ANCOR, 89\% компаний отметили рост эффективности сотрудников, работающих удаленно. Тем не менее, 76\% опрошенных считают, что наиболее эффективным форматом работы является гибридная, предполагающая сочетание работы в офисе и удаленной занятости [9].

Анализ результатов нескольких месяцев вынужденной удаленной работы позволяет выявить как преимущества, так и недостатки указанной формы занятости. В целом отношение к удаленной работе изменилось в лучшую сторону: по итогам исследования, проведенного hh.ru, на вопрос о желании продолжить работать удаленно после снятия ограничительных мер в июле 2020 года положительно ответили $72 \%$ опрошенных, а в апреле 2020 - всего 57\%. Определенно против продолжения удаленной работы в июле было 9\% опрошенных, а в апреле - 14\% [10].

Всероссийский центр изучения общественного мнения (ВЦИОМ) и ООО «Социал Бизнес Групп» (SBG) исследовали причины, влияющие на положительное или отрицательное отношение работников к переходу на удаленную работу [11]. Ключевые преимущества, отмеченные в ходе опроса, представлены на рис. 1 (каждый опрошенный мог выбрать до трех вариантов ответов).

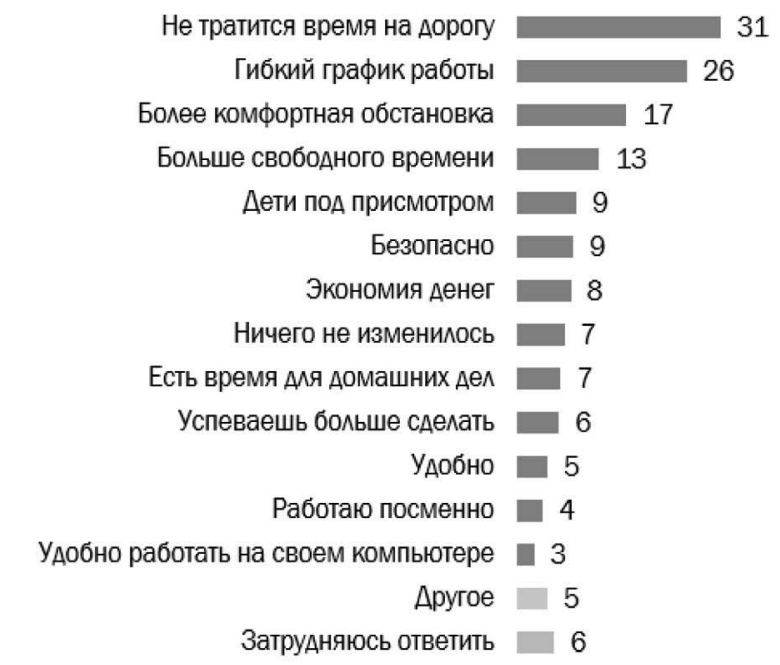

Источник: совместное исследование ВЦИОМ и SBG.

Рис. 1. Преимущества удаленной работы, с точки зрения работников, \%
С позиции работодателей, некоторые отмеченные пункты, согласно результатам указанного совместного исследования ВЦИОМ и SBG, также могут быть оценены положительно. В частности, более комфортная для работника обстановка, не требующая затрат со стороны компании (17\%), общее удобство (5\%) и удобство работы на своем компьютере (3\%), а также большая продуктивность (6\%). Некоторые пункты следует признать нейтральными для работодателя - экономия времени на дорогу (31\%) и денег (8\%), а также отмеченное работниками отсутствие изменений (7\%).

Однако ряд пунктов вызывает вопросы: увеличение свободного времени (13\%), возможность присматривать за детьми (9\%) и заниматься домашними делами (7\%), а также гибкий график работы (26\%). Эти факторы могут негативно сказываться на продуктивности работы и требуют от работодателя применения специфических инструментов контроля.

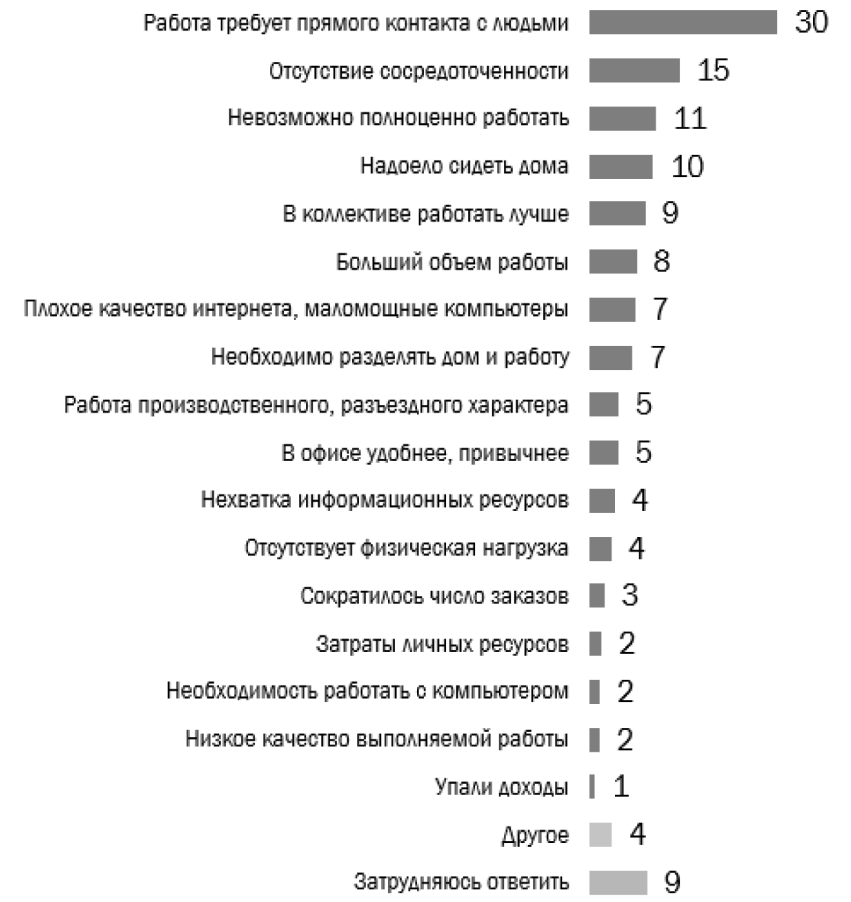

Источник: совместное исследование ВЦИОМ и SBG.

Рис. 2. Недостатки удаленной работы, с точки зрения работников, \%

Недостатки удаленной работы, отмеченные работниками, представлены на рис. 2. Если исключить случаи объективной невозможности осуществлять выполнение должностных обязанностей из дома - когда работа требует прямого контакта с людьми (30\%) или имеет производственный, разъездной характер (5\%) - одними из самых часто называемых недостатков становятся отсутствие сосредоточенности (15\%) и невозможность полноценной работы (11\%). 
В целом, все недостатки удаленной работы могут быть разделены на определенные группы:

1. связанные с организацией дистанционного рабочего процесса, такие как снижение скорости коммуникации, невозможность лично оперативно решить текущие вопросы;

2. связанные с режимом самоизоляции - отвлекающие моменты в виде присутствия членов семьи (в том числе детей), нехватка движения и недостаток общения;

3. связанные с самоорганизацией. В условиях ослабления внешнего контроля многим работникам становится сложно сосредоточиться на рабочих вопросах, не отвлекаться на домашние дела и личную жизнь;

4. связанные с оснащением рабочего места - у многих работников дома отсутствуют достаточно мощные компьютеры, удобные столы и стулья, недостаточно хорошая связь [12].

\section{Рекомендашии по повышению эффективности рабочих прочессов при уАаленной работе и осушествлению сошиально-трудового мониторинга}

Большая часть рассмотренных проблем может быть охарактеризована как организационная, в этой связи, в решении указанных проблем, по нашему мнению, должны участвовать как работники, так и работодатели путем обеспечения сотрудников оборудованием, нужным для исполнения должностного функционала, а также отладки, перестройки и модернизации имеющихся бизнеспроцессов, их адаптации к новым условиям труда.

Среди других проблем, с которыми столкнулись работодатели, можно отметить необходимость трансформации системы контроля за качеством и сроком выполнения задач при удаленной занятости. Традиционно контроль принято разделять на три взаимосвязанные категории: предварительный, текущий и итоговый. В условиях удаленной занятости эти формы контроля сохраняются. Особое внимание, по нашему мнению, при этом следует уделять предварительному и текущему контролю, которые позволяют понять, правильно ли сотрудник интерпретировал поставленную задачу, сроки и порядок ее выполнения $[13,14]$.

Контроль работы при удаленной занятости имеет свои особенности и специфические инструменты. Если в офисе у руководителя имеется возможность прийти на рабочее место сотрудника и проверить качество выполняемой работы, то при удаленной работе такой контроль физически невозможен. Одним из вариантов организации системы социально-трудового мониторинга в этом случае является составление поэтапного плана выполнения работы и регулярное информирование сотрудником о результатах выполнения этого плана, а также о проблемах, с которыми он сталкивается при выполнении своих должностных обязанностей (нехватка информации, недостаток технических возможностей, отсутствие информации от коллеги по проекту и т.д.).

Решение этой задачи, с учетом территориально распределенного характера деятельности при удаленной работе, традиционными методами затруднительно, т.к. приведет к обюрокрачиванию, следовательно, к снижению оперативности рабочих процессов, снижению эффективности работы. В этой связи, следует продумать возможность и целесообразность применения, например, цифровых инструментов удаленного контроля за активностью сотрудников за компьютерами (CleverControl или аналогичных).

Но одними лишь техническими решениями, по нашему мнению, обойтись нельзя. Требуются и организационные изменения, т.к. понимание факторов, снижающих продуктивность в каждом конкретном случае, позволяет своевременно реагировать на недочеты в организации удаленной работы и устранять их. Регулярное сообщение о достигнутых результатах позволяет избежать прокрастинации, поскольку сотрудники понимают, что несмотря на отсутствие рядом руководителя, результаты их работы непрерывно оцениваются и контролируются.

Соблюдение баланса между контролем и другими функциями менеджмента - важное условие эффективной организации рабочего процесса в условиях удаленной занятости. Отсутствие контроля приводит к срыву сроков и некачественному выполнению поставленных задач, излишний контроль (ежедневные онлайн-совещания и сборы, требования отчета в конце дня о проделанной работе, установка программного обеспечения, позволяющего следить за тем, что происходит на компьютере сотрудника и т.д.) снижает мотивацию и приводит к росту недовольства работодателем со стороны работников. Важно учитывать, что баланс «контрольсвобода» для каждого работника будет разным: например, если сотрудник работает недавно, то ему, как правило, требуется больше контроля, чем тому, кто давно трудится в компании. Кроме этого, у каждого человека разные способности к самоорганизации и самодисциплине.

Внедрение досок задач и трекеров, наглядно отображающих список задач, над которыми работает каждый сотрудник, и ход их выполнения, является эффективным инструментом социально-трудового мониторинга и помогает работодателю следить за качеством работы персонала без излишнего (раздражающего) контроля. Наибольшую популярность среди подобных инструментов получили Trello, Asana и Jira. Разделение задач на «запланированные» и «выполненные» позволяет руководите- 
лю оценить продуктивность работы сотрудников, обеспечивает оперативность и удобство работы.

Среди других инструментов эффективной организации труда и социально-трудового мониторинга в условиях перехода на удаленную работу можно выделить:

- регулярное обсуждение с сотрудником его индивидуальных задач (телефонные звонки, сообщения), направленное на конкретизацию этапов выполнения работы и решение возникающих текущих проблем;

- онлайн-конференции и планерки для постановки общих целей, контроля работы над проектом всей команды и т.д.;

- внедрение CRM, ERP и других корпоративных информационных систем, позволяющих автоматизировать рабочие процессы и оценивать работу сотрудника удаленно [15].

\section{Зак^ючение}

Большинство сотрудников и работодателей увидели в удаленной занятости, импульс к развитию которой дала пандемия COVID-19, не только проблемы и препятствия для традиционной организации деятельности, но и новые возможности. Для работодателей это, прежде всего, возможности снижения затрат (арендных платежей), для сотрудников - возможность экономии време- ни на дорогу, распределения времени на выполнение личных и рабочих задач. По результатам опроса, 70\% компаний рассматривают вариант сохранения нового формата занятости, среди сотрудников этот показатель также высок и составляет $60 \%$.

Это весьма значительные показатели. Причем они не связаны напрямую с пандемией, хотя и индуцированы ею. Отметим, что именно в условиях пандемии удаленная работа приносит работодателям ряд дополнительных преимуществ. Так, перевод сотрудников на удаленный режим работы позволяет работодателю избежать дополнительных расходов, связанных с необходимостью соблюдения санитарных норм в условиях пандемии, обеспечения персонала одноразовыми масками и перчатками, контроля за состоянием их здоровья.

Несмотря на ряд положительных эффектов, связанных с удаленной работой, остается ряд открытых вопросов, касающихся использования работниками в удаленном режиме собственных ресурсов для решения служебных задач. Не проработанным с теоретических, практических и нормативных позиций остается вопрос компенсации затрат работника при удаленной работе на электроэнергию, использование личной техники и программного обеспечения, оплату телефонной и Интернет-связи и т.д. По мнению авторов, анализ этих аспектов может послужить направлением для дальнейших исследований.

\section{ЛИТЕРАТУРА}

1. Экономика коронакризиса: вызовы и решения: Сб. науч. трудов / под ред. Р.М. Нижегородцева. М.: 000 «НИПКЦ Восход-А», 2020. 282 с.

2. Вертакова Ю.В., Андросова И.В., Бедакова М.С., Леонтьев Е.Д., Вселенская И.В. Управление трансформацией предпринимательских структур. Курск: Университетская книга, 2020. 197 с.

3. Институциональная трансформация социально-экономических систем в условиях цифровизации: состояние, тренды, проблемы и перспективы: монография. Курск: Университетская книга, 2020. 294 с.

4. Вертакова Ю.В., Зарецкая В.Г., Плотников В.А. COVID-19 и европейская интеграция: станет ли пандемия коронавируса триггером распада Европейского Союза? // Управление устойчивым развитием. 2020. № 3 (28). С. 5-16.

5. Письмо Министерства труда и социальной защиты РФ от 23 апреля 2020 г. № 14-2/10/П-3710 «0 направлении рекомендаций по применению гибких форм занятости в условиях предупреждения распространения новой коронавирусной инфекции на территории РФ». [Электронный ресурс]. Режим доступа: https://base.garant.ru/73961439 (дата обращения 07.09.2020).

6. Трудовой кодекс Российской Федерации от 30 декабря 2001 г. № 197 Ф3 (ред. от 31.07.2020) (с изм. и доп., вступ. в силу с 13.08.2020) // Собрание законодательства РФ. 2002. № 1 (ч. 1). Ст. 3.

7. Котляров И. Нестандартные формы занятости // Общество и экономика. 2015. № 1-2. С. 203-218.

8. Лютов Н.Л. Дистанционный труд: опыт Европейского Союза и проблемы правового регулирования в России // Lex Russica. 2018 . № 10 (143). С. 30 -39.

9. Работники увидели рост своей эффективности на удаленке. [Электронный ресурc]. Режим доступа: https://www.rbc.ru/society/25/08/2020/5f440e2d9a7 $947 f f 84970495$ (дата обращения 15.10.2020).

10. Ивушкина А. Режим заботы. [Электронный ресурс]. Режим доступа: https://iz.ru/1043466/anna-ivushkina/rezhim-zaboty-72-sotrudnikov-khotiat-prodolzhitrabotat-udalenno (дата обращения 15.09.2020).

11. Цифровая грамотность и удаленная работа. [Электронный ресурс]. Режим доступа: https://wciom.ru/index.php?id=236\&uid=10280 (дата 0бращения 10.09.2020).

12. Гурова И.М. Дистанционная работа как тренд времени: результаты массового опыта // МИР (Модернизация. Инновации. Развитие). 2020. Т. 11. № 2. С. 128-147.

13. Кузьбожев Э.Н., Рябцева И.Ф. Практика системного анализа проблемы повышения производительности труда // Экономический анализ: теория и 
практика. 2011. № 1 (208). С. 17-24.

14. Шульгина Ю.В., Мальцева И.Ф. Роль социально-трудового мониторинга в современных подсистемах менеджмента организаций // Известия Юго-Западного государственного университета. Серия: Экономика. Социология. Менеджмент. 2019. Т. 9. № 1 (30). С. 38-46.

15. Шульгина Ю.В., Мальцева И.Ф. Трансформация системы управления персоналом: цифровые технологии в социально-трудовом мониторинге // Цифровая экономика: проблемы и перспективы развития: сборник научных статей Межрегиональной научно-практической конференции. Курск, 2019. С. 214-219.

( ) Шульгина Юлия Валерьевна (jvl@inbox.ru), Вертакова Юлия Владимировна (vertakova7@yandex.ru),

Мальцева Ирина Федоровна (irina-fedorovna@inbox.ru), Плотников Владимир Александрович (Plotnikov_2000@mail.ru).

Журнал «Современная наука: актуальные проблемы теории и практики»

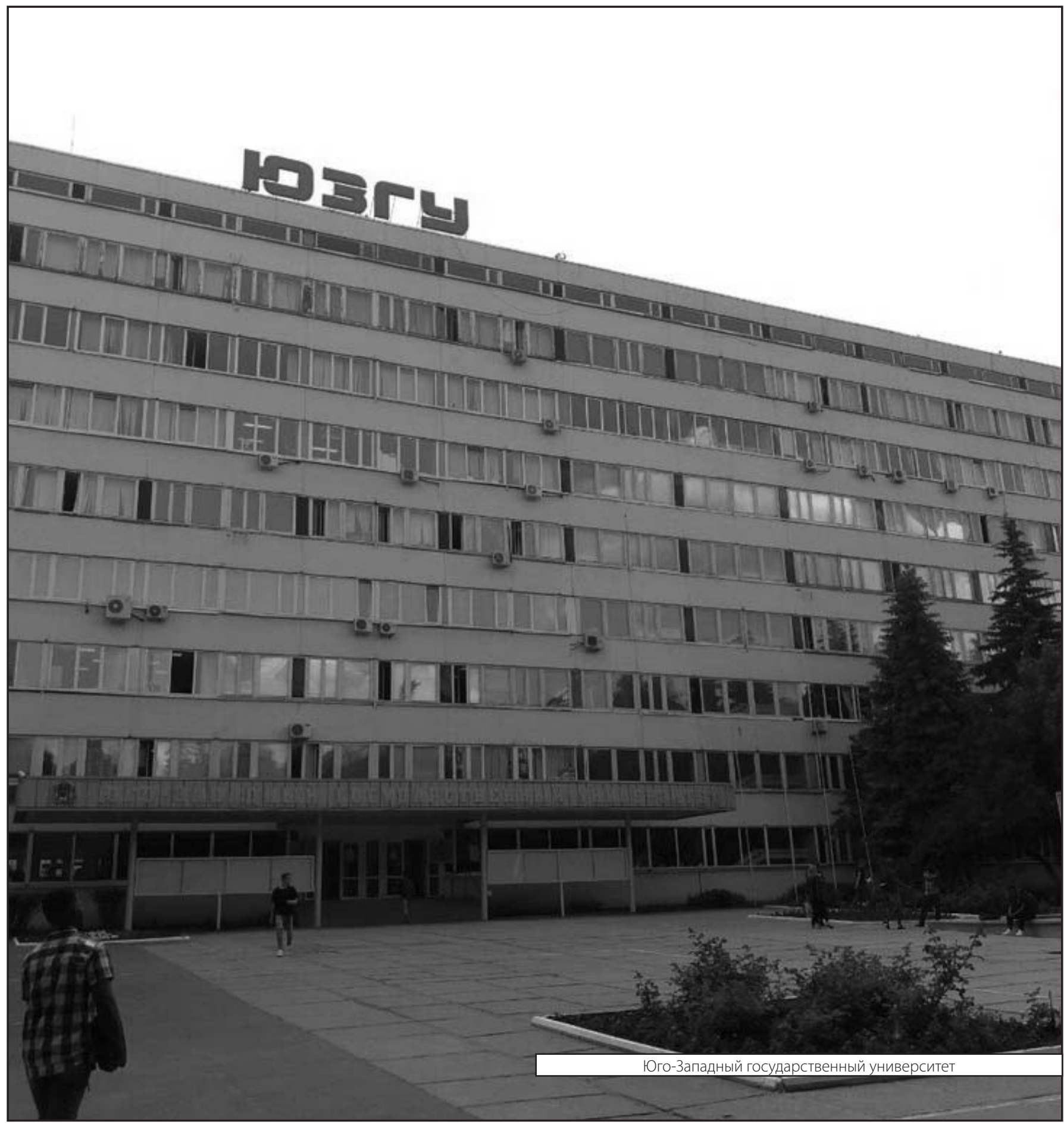

